\title{
RUPTURE EXTENT OF THE 1978 MIYAGI-OKI, JAPAN, EARTHQUAKE AND SEISMIC COUPLING IN THE NORTHERN HONSHU SUBDUCTION ZONE
}

\author{
Bart W. Tichelaar and Larry J. Ruff
}

Department of Geological Sciences, The University of Michigan, Ann Arbor

Abstract. Underthrusting at subduction zones can cause large earthquakes at shallow depths, but is always accommodated by aseismic creep below a certain depth. This transition depth is referred to as the depth of seismic coupling and can be directly observed in a subduction zone as the lower depth extent of significant moment release of the deepest large underthrusting earthquakes. In 1978, a large $\left(M_{s}=7.5\right)$ earthquake occurred off the coast of Miyagi Prefecture in northern Honshu. Its focal mechanism represents underthrusting of the Pacific plate beneath Honshu. Since the hypocenter is located $150 \mathrm{~km}$ landward from the trench and there are no other large interplate earthquakes further landward from the trench axis, this event defines the maximum depth of the coupled zone.

The lower limit of significant moment release of the Miyagi-Oki earthquake is obtained by analysis of the longperiod $P$ waves. The deconvolved source time function consists of a dominant single pulse with peak moment release at $12 \mathrm{~s}$ and a total duration of $18 \mathrm{~s}$. The rupture extent of this dominant pulse does not extend deeper than $40 \mathrm{~km}$, thus the transition from coupled to uncoupled in northern Honshu occurs at or above $40 \mathrm{~km}$ depth.

\section{Introduction}

An important characteristic of interplate seismicity in subduction zones is that no large underthrusting earthquakes occur below a certain depth. In other words, underthrusting in subduction zones can cause large earthquakes at shallow depths, but is accommodated by aseismic creep below a certain depth. The nature of this transition from seismically coupled at shallow depths to uncoupled at deeper depths (Figure 1) is not well understood. It is apparently more complex than continental strike slip environments, where the

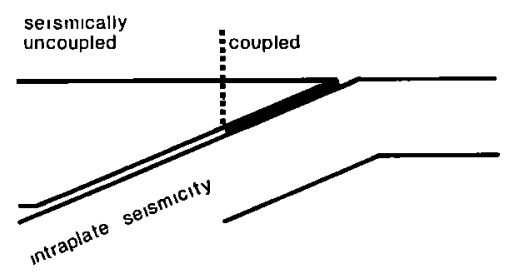

Fig. 1. Underthrusting at subduction zones can cause large interplate earthquakes at shallow depth (dark part of the plate interface), but is always accommodated by aseismic creep below a certain depth; intraplate seismicity extends much deeper. The lack of deep interplate seismicity suggests a change in the state of mechanical coupling between the plates from seismically coupled at shallow depths to uncoupled at deeper depths.

Copyright 1988 by the American Geophysical Union.

Paper number 88GL03425.

0094-8276/88/88GL-03425\$03.00 depth dependence is explained by the pressure/temperature rheological behavior of crustal rocks [Sibson,1984; Chen and Molnar,1983]. Various phenomena such as vertical transport of material, presence or absence of subducting sediments, and phase changes may or may not add complexities to the nature of seismic coupling in subduction zones.

As a first step to study the details of seismic coupling, we want to determine the cut-off depth of seismic coupling, and its regional variations. The seismically coupled zone is the depth range of the plate interface that is capable of producing an underthrusting earthquake. This implies that the "complete" mapping of the coupled/uncoupled transition involves the determination of accurate source depths for all interplate seismicity from the highest to the lowest magnitude; this ideal global mapping is not possible. For a first order mapping of the transition depth, we only include seismicity with a magnitude larger than six. There are two main reasons that our first order mapping uses this magnitude threshold. First, the basic transition depth should be based on earthquakes with major moment release rather than minor earthquakes. The second reason is a practical one, and in fact more compelling: in the future, we shall extend this study of coupling in northern Honshu to a globally uniform study. The method we use to determine depth inverts the entire long period $P$ wave form, and can be applied to earthquakes as large as $\mathbf{M}_{\mathbf{w}}=7.5$. Because of the quality of available waveforms, the method can however not be used for magnitudes smaller than 6.

For the northern Honshu (Japan) region, we study the rupture extent of the June $12, \mathrm{M}_{\mathrm{s}}=7.5$ Miyagi-Oki earthquake. This large earthquake occurred off the Pacific coast of northern Honshu, and belongs to the group of underthrusting events that are furthest landward from the trench axis between 37 and $39^{\circ} \mathrm{N}$ (Figure 2, Table 1). The 1978 Miyagi-Oki earthquake is at least one order of magnitude larger than the other events listed in Table 1. Seno et al. [1980] studied the 1978 earthquake using long-period surface and body waves. They determined a seismic moment of $3 \times 10^{27}$ dyn $\mathrm{cm}$ and a focal mechanism (dip $20^{\circ} \mathrm{W}$, slip $76^{\circ}$,

TABLE 1. Interplate earthquakes between 37 and $39^{\circ} \mathrm{N}$ with magnitude $M=M_{w}>6$ or $M=m_{b}>6$ that are furthest landward from the trench axis. The depth uncertainty is twice the standard deviation. References: 0 Yoshii [1979], 1 NEIS, 2 Harvard catalog, 3 ISC, 4 this study.

\begin{tabular}{|c|c|c|c|c|}
\hline $\begin{array}{l}\mathrm{date} \\
\mathrm{m} / \mathrm{d} / \mathrm{y}\end{array}$ & $\mathbf{M}$ & $\begin{array}{c}\text { epicenter } \\
\text { lat }^{\circ} \mathrm{N} \text { lon }{ }^{\circ} \mathrm{E}\end{array}$ & $\begin{array}{l}\text { depth } \\
\text { [km] }\end{array}$ & $\begin{array}{c}\text { references } \\
\text { epicenter/depth(s) }\end{array}$ \\
\hline $\begin{array}{l}4 / 16 / 87 \\
4 / 22 / 87 \\
4 / 7 / 87 \\
8 / 12 / 85 \\
6 / 12 / 78 \\
1 / 17 / 67 \\
7 / 5 / 68 \\
5 / 31 / 82 \\
11 / 30 / 86 \\
11 / 19 / 73\end{array}$ & $\begin{array}{l}6.0_{\mathrm{w}} \\
6.6_{\mathrm{w}} \\
6.6_{\mathrm{w}} \\
6.4_{\mathrm{w}} \\
7.6_{\mathrm{w}} \\
5.9_{\mathrm{b}} \\
6.0_{\mathrm{b}} \\
6.1_{\mathrm{w}} \\
6.0_{\mathrm{w}} \\
6 . \mathrm{w}_{\mathrm{b}}\end{array}$ & $\begin{array}{ll}37.02 & 141.44 \\
37.09 & 141.39 \\
37.35 & 141.68 \\
37.74 & 141.73 \\
38.23 & 142.02 \\
38.33 & 142.20 \\
38.54 & 142.14 \\
38.76 & 142.22 \\
38.86 & 141.97 \\
38.99 & 141.93\end{array}$ & $\begin{array}{l}32 \\
33 \\
31 \\
38.7 \pm 2.4 \\
48,40 \pm 5 \\
40 \\
44,44 \pm 4.4 \\
40.5 \pm 4.6 \\
42 \pm 3.2 \\
49,56 \pm 3.6\end{array}$ & $\begin{array}{c}1 / 2 \\
1 / 2 \\
1 / 2 \\
1 / 2 \\
3 / 3,4 \\
3 / 0 \\
3 / 0,3 \\
3 / 2 \\
1 / 2 \\
3 / 0,3\end{array}$ \\
\hline
\end{tabular}




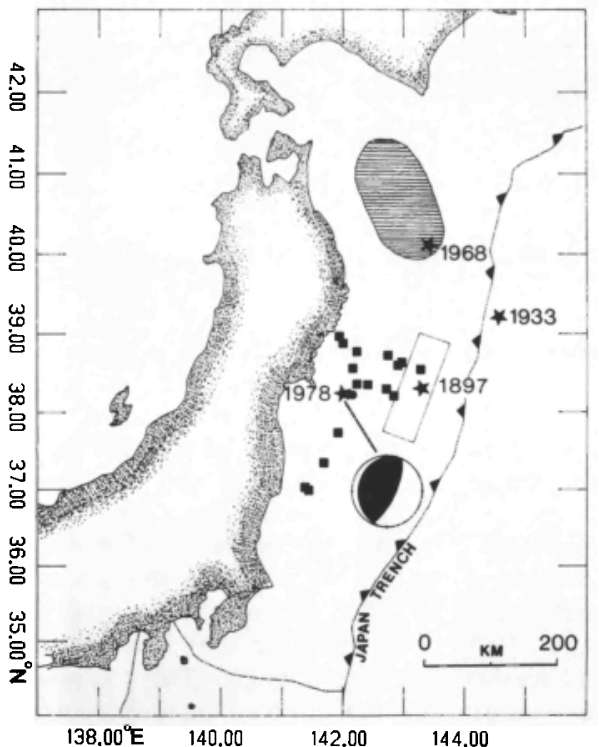

Fig. 2. Tectonic setting. The 1978 mainshock (star) and its foreshock (dot) epicenters are located far landward from the trench axis. The squares indicate local interplate seismicity with $M>6$. The hachured area is the large asperity that ruptured in the great $M_{w}=8.2$ Tokachi-Oki earthquake of 1968 . The epicenters for the large 1933 and 1897 earthquakes are also shown as stars. The rectangular region is the seismic gap identified by Seno [1979].

strike $190^{\circ}$ ) that represents underthrusting of the Pacific plate beneath Honshu on a shallowly westward dipping plane (F1gure 2). According to these researchers, rupture extended down to $50 \mathrm{~km}$, corresponding with a group of small aftershocks that occurred around this depth, and this result

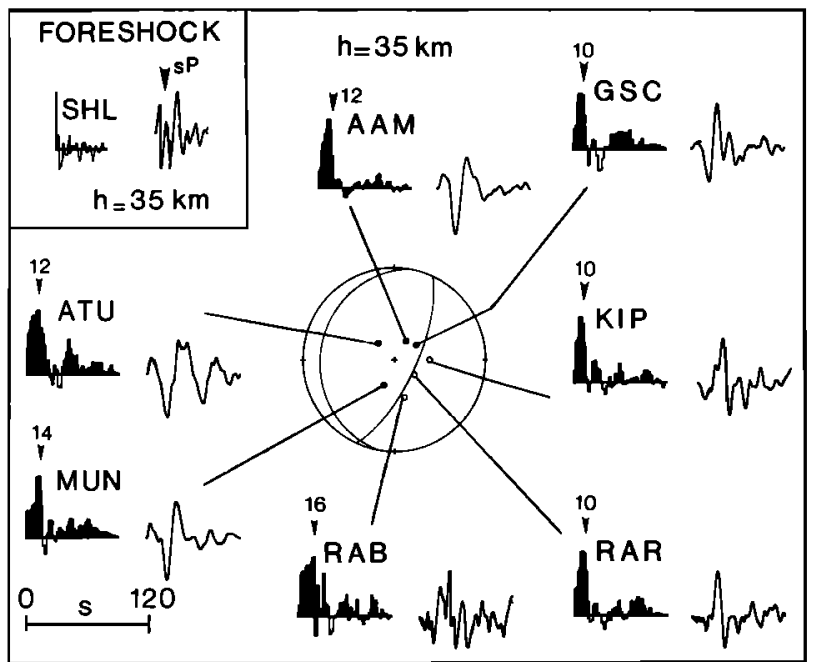

Fig 3 Source time functions for the Miyagi-Oki mainshock and foreshock. Deconvolved mainshock source functions are shown for 7 stations, with the observed and synthetic seismograms on their right (plotted on top of each other). Station codes and locations on the focal sphere are also shown. The Green's functions are calculated for a point source at 35 $\mathrm{km}$ depth. The numbers above the arrowheads are the times picked for the truncation of moment release. Inset: seismogram of the foreshock with a clear $s P$ phase ( $P P$ depth phase is nodal). Time scale in inset is time scale in man figure. appears to agree with the ISC depth of $48 \mathrm{~km}$. Thus the 1978 Miyagi-Oki earthquake can be used for a first order mapping of the bottom edge of the coupled zone, and deserves a special study of focal depth.

Figure 2 shows the tectonic setting of the 1978 earthquake. The figure shows that the hypocenter is located at the downdip edge of the coupled zone. Several other large earthquakes have occurred in this region. A large asperity ruptured in the great 1968 Tokachi-Oki underthrusting earthquake $\left(M_{w}=8.2\right)$ [Schwartz and Ruff, 1985]. This large asperity defines a strongly coupled region on the plate interface. The $1933 M_{s}=8.5$ Sanriku earthquake represents normal faulting of the entire oceanic lithosphere at the trench axis [Kanamori, 1971]. This normal faulting event, combined with the fact that no great thrust earthquakes have occurred in the latitude range from 39 to $40^{\circ} \mathrm{N}$ for at least the last 200 years, suggests that the plate interface in this region is weakly coupled [Kawakatsu and Seno, 1983]. In 1897 , a large $\left(M_{J M A}=7.7\right.$ ) earthquake occurred $150 \mathrm{~km}$ off the coast, east of the Miyagi-Oki epicenter. A similar event may have happened in 1793. Thus, Seno [1979] delineated a rectangular area in the vicinity of the 1897 event that he postulated to be a seismic gap (Figure 2).

\section{$P$ waves for the 1978 Miyagi-Oki earthquake.}

In order to determine the depth extent of significant moment release, source time functions have been deconvolved from long-period WWSSN $P$ waves using the method of Ruff and Kanamori [1983]. Figure 3 shows these source tıme functions for seven different stations, with the corresponding synthetic and observed seismograms plotted together on the right. Green's functions are calculated for a point source at $35 \mathrm{~km}$ depth in a halfspace with a $800 \mathrm{~m}$ ocean layer. The mainshock time function consists of a dominant single pulse with peak moment release at $12 \mathrm{~s}$ and a total duration of 18 $s$ (Figure 3). The source time functions show directivity effects with a pulse duration $6 \mathrm{~s}$ greater for stations to the east. The truncation of moment release occurs at $10 \mathrm{~s}$ for eastern azimuths and at 12 to $16 \mathrm{~s}$ for western stations. Although directivity is not the primary topic of this research, we used tomographic imaging of moment release on the fault plane [Ruff,1987] and found a preferred rupture propagation direction of $N 70^{\circ} \mathrm{E}$. Thus, the rupture was predominantly updip.

About 8 minutes before the mainshock, a $M_{s}=5.9$ foreshock occurred east of the epicenter (Figure 2). Seno et al. [1980] found that its focal mechanism is consistent with that of the mainshock. A clearly visible depth phase can be distinguished [Figure 3, inset]. This $s P$ phase has been observed at five stations (Table 2) and corresponds to a depth of $31 \pm 1$ $\mathrm{km} \quad\left(v_{p}=6.7 \mathrm{~km} / \mathrm{s}, v_{p} / v_{\mathrm{s}}=1.732\right)$. The $p P$ depth phase for all stations in Table 2 is nodal or near nodal and cannot be observed. For the mainshock, it is impossible to visually iden-

TABLE 2. Arrival time of the $s P$ depth phase relative to the first $P$ arrival, and the corresponding hypocentral depth for the June 12, 1978 foreshock of the Miyagi-Oki earthquake $\left(v_{p}=6.7 \mathrm{~km} / \mathrm{s}, v_{p} / v_{a}=1.732\right)$.

\begin{tabular}{ccc}
\hline station code & T $_{\text {BP-P }}$ [s] & depth [km] \\
\hline SHL & 11.0 & 29.9 \\
QUE & 12.2 & 32.1 \\
KBL & 11.4 & 30.1 \\
JER & 12.1 & 30.9 \\
NDI & 12.1 & 32.3 \\
& & average: $31 . \pm 1 . \mathbf{k m}$ \\
\end{tabular}




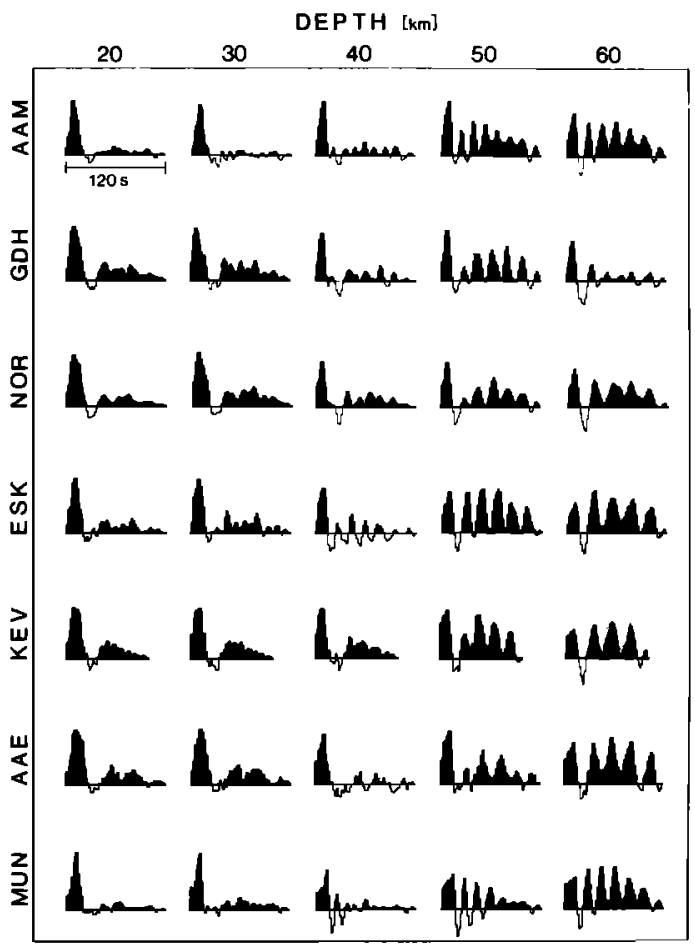

Fig. 4. Source time functions at 7 stations (vertical) deconvolved for a point source Green's function at 5 different depths (horizontal). Note the spurious multiple pulses that appear at 50 and $60 \mathrm{~km}$ depth.

tify the depth phases since their time separation from the direct $P$ is smaller than the duration of the mainshock. Depth is now determined by deconvolving source time functions from the $P$ wave data for point source Green's functions at different depths. The most important parameter in the deconvolution is the separation time between the direct $P$ and depth phases. The separation time can be resolved through waveform analysis and is translated into depth given some seismic velocity. Using Yoshii's [1977, 1979] cross section of crustal structure beneath northeastern Honshu, an average $P$ wave velocity of $6.7 \mathrm{~km} / \mathrm{s}$ is chosen to be appropriate. Figure 4 shows the deconvolved source time functions for 7 stations and 5 depths ranging from 20 to $60 \mathrm{~km}$. Changes in the Green's function caused by an incorrect assumed depth can

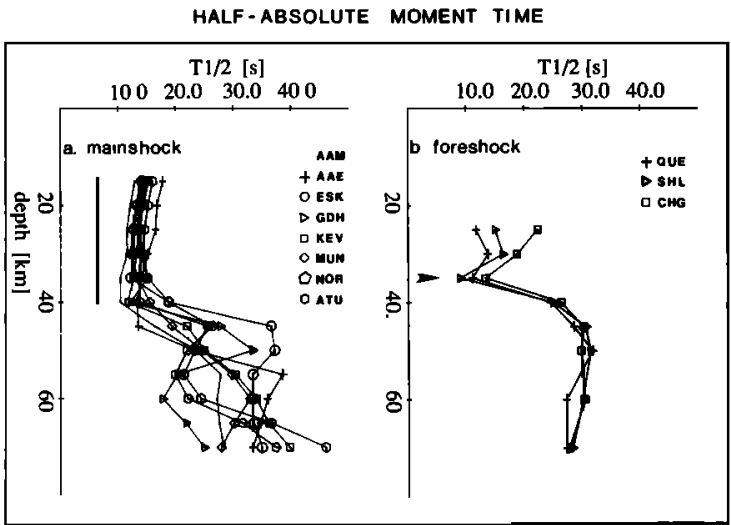

F1g. 5. Half absolute moment time $\left(T_{1 / 2}\right)$ for various stations for the mainshock (a) and the foreshock (b). For the mainshock, $T_{1 / 2}$ increases below $40 \pm 5 \mathrm{~km}$ For the foreshock this increase occurs below $35 \mathrm{~km}$. always be compensated in the source time function, producing the same seismogram. Thus there is a considerable tradeoff between depth and source function for single-station deconvolution (see Christensen and Ruff, 1985). However, Figure 4 shows that for depths of 50 and $60 \mathrm{~km}$ the apparent complexity of the source becomes unacceptably high. Instead of showing a simple single pulse of a shorter duration, the moment release shows quasi-periodic oscillations. This complexity results from depth overestimation. The source time functions do not show significant changes over the depth range of 20 to $40 \mathrm{~km}$, as depth underestimation is difficult to assess. The above approach to depth estimation has been developed by Christensen and Ruff [1985] and their synthetic tests for both point and finite sources show that the change from "simple" to "complicated" source time functions pinpoints the lower limit of significant moment release. To evaluate this limit, they defined a measure of simplicity, the half absolute moment time $\left(T_{1 / 2}\right)$, which is the time when the cumulative absolute value of the time function equals half of the total sum of the absolute time function.

For the mainshock of the 1978 earthquake, the values of $T_{1 / 2}$ at depth increments of $5 \mathrm{~km}$ are plotted in Figure $5 \mathrm{a}$ for eight different stations. We see a clear increase in $T_{1 / 2}$ below $40 \mathrm{~km}$. The lower bound of significant moment release is thus constrained at $40 \pm 5 \mathrm{~km}$. $T_{1 / 2}$ curves for three stations that recorded the small foreshock are shown in Figure $5 b$. $T_{1 / 2}$ has a minimum at $35 \mathrm{~km}$. Hence the estimated foreshock depth based on waveform analysis is $35 \pm 5 \mathrm{~km}$, which agrees with the more precise depth of $31 \pm 1 \mathrm{~km}$ determined by direct measurement of the observed $S P$ phase. This result gives us more confidence in our lower bound on the mainshock moment release. The observation of a group of small aftershocks around $50 \mathrm{~km}$ depth by Seno et al. [1980] may indicate that interplate seismicity with a magnitude smaller than six is possible below the depth range that can produce a large underthrusting earthquake.

Figure 6 shows the epicenters of four well-located aftershocks within one day after the mainshock. The locations are from the ISC, and $m_{b}$ ranges from 4.1 to 5.9. A circular region that encloses these shocks has an area that is compatible with the expected rupture area for a $M_{s}=7.5$ earthquake. In addition, the updip af tershock locations are in agreement with the observed mainshock directivity, i.e. a rupture azimuth of $N 70^{\circ} \mathrm{E}$. The fact that rupture does not

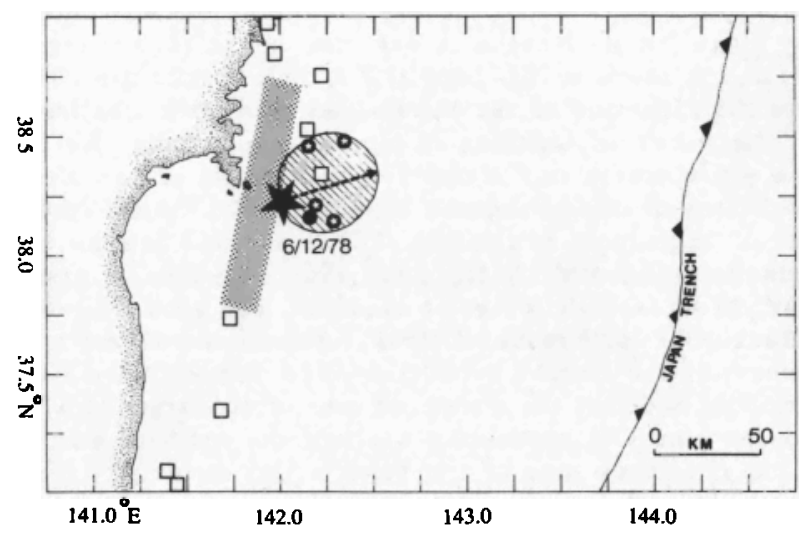

Fig. 6. Epicenters for the 1978 Miyagi-Oki mainshock (large star), its foreshock (dot) and well located 1-day aftershocks (open stars), together with those underthrusting earthquakes (M>6, Table 1) that define the bottom edge of the coupled zone (open squares). The aftershocks define an area (hachured) that is compatible with the expected rupture area of a $M_{s}=7.5$ earthquake. The arrow shows the preferred easterly rupture propagation azimuth. The dotted bar depicts the transition between coupled and uncoupled. 


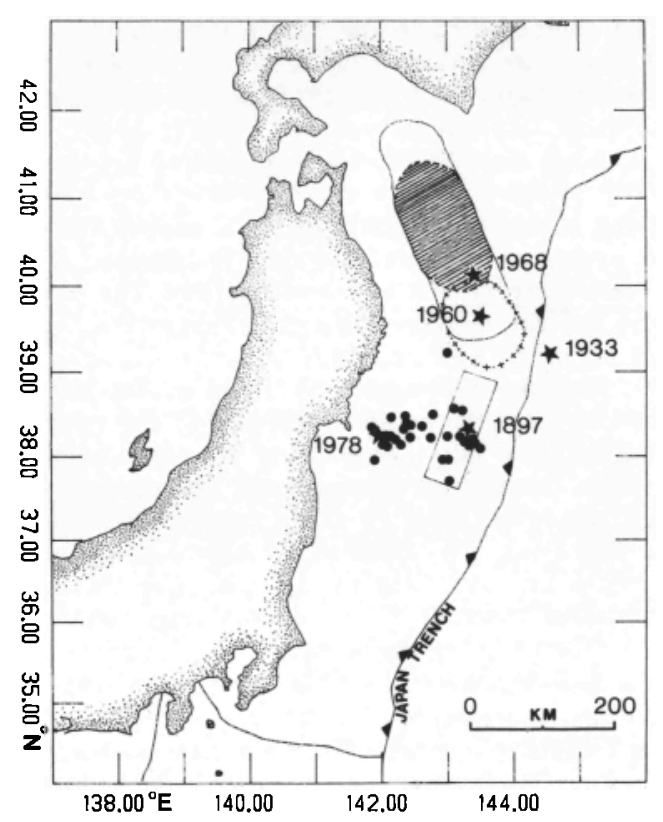

Fig. 7. Same as Figure 2, with the addition of the epicenter of the $1960 \mathrm{M}_{\mathrm{s}}=7.5$ Sanriku-Oki earthquake and its 3-day af tershock area (enclosed by the plus-dotted line). The solid line surrounding the 1968 asperity and 1960 epicenter delineates the 1-day aftershock zone of the 1968 TokachiOki earthquake. Note that the 1960 aftershock area does not expand into the big asperity (hachured). Also shown are the 1978 Miyagi-Oki 10-day aftershocks (solid dots). Note that the 1978 aftershock area does expand into the 1897 zone.

extend deeper than about $40 \mathrm{~km}$ suggests that the subduction zone is seismically uncoupled below this depth.

\section{Seismic coupling and the aftershock area expansion}

Figure 7 shows the aftershocks that occurred up to ten days after the Miyagi-Oki earthquake (ISC locations). Note that the aftershock area has expanded trenchward relative to the one-day aftershock area. This expansion was characterized by Tajima and Kanamori [1985] on the basis of NEIS locations and they showed that the expansion rate was unusually high. The aftershocks expand into the rectangular region which was identified by Seno [1979] as a seismic gap. What does the expansion of the Miyagi-Oki aftershock area imply for the nature of coupling in the rectangular area? We can look elsewhere in this region for an example of the aftershock area of one earthquake expanding into the af tershock area of subsequent earthquake. The large 1960 Sanriku-Oki earthquake followed by the great 1968 Tokachi-Oki earthquake is an example of such a sequence. The great $\left(M_{w}=8.2\right)$ Tokachi-Oki earthquake of 1968 ruptured the northermost segment of the Honshu subduction zone. Schwartz and Ruff [1985] showed that the aftershock area of the large $\left(M_{s}=7.5\right)$ 1960 Sanriku-Oki earthquake overlaps the southern portion of the aftershock zone of the Tokachi-Oki earthquake (Figure 7). While this implies that the 1968 event reruptured part of the 1960 fault zone, it is important to realize that the 1960 aftershocks do not expand into the large asperity of the 1968 event (hachured area in Figure 7). To now use the 1960 Sanriku-Oki event as a hypothetical analog for the 1978 Miyagi-Oki earthquake, we conclude that there is no large asperity trenchward of the 1978 event.

\section{Conclusions}

The 1978 Miyagi-Oki earthquake is the largest underthrusting event along northern Honshu between 37 and $39^{\circ} \mathrm{N}$ in recent years. Rupture of the 1978 earthquake does not extend deeper than $40 \pm 5 \mathrm{~km}$. Thus, to the first order, the seismically coupled zone in this region extends no deeper than $40 \pm 5 \mathrm{~km}$.

A conclusion can also be reached concerning the variation in seismic coupling within the coupled interface zone. The 1978 Miyagi-Oki earthquake defines a seismically coupled region that extends about $50 \mathrm{~km}$ updip from the epicenter, as determined by the 1-day aftershock area and source time function directivity. But the aftershock area expands another $100 \mathrm{~km}$ to the trench in ten days. This suggests that the southern half of the 1897 zone is weakly coupled.

Acknowledgments. We acknowledge the helpful criticisms of the anonymous reviewers. The earthquake research program at the University of Michigan is supported by grants from the National Science Foundation (EAR8351515 and EAR8407786) to LJR.

\section{References}

Chen, W.P., and P. Molnar, Focal depths of intracontinental and intraplate earthquakes and their implications for the thermal and mechanical properties of the lithosphere, J. Geophys. Res., 88, 4183-4214, 1983.

Christensen, D.H., and L.J. Ruff, Analysis of the trade-off between hypocentral depth and source time function, Bull. Seismol. Soc. Am., 75, 1637-1656, 1985.

Kanamori, H., Seismological evidence for a lithospheric normal faulting - The Sanriku earthquake of 1933, Phys. Earth Planet. Inter., 4, 289-300, 1971.

Kawakatsu, H., and T. Seno, Triple seismic zone and the regional variation of seismicity along the northern Honshu arc, J. Geophys. Res., 88, 4215-4230, 1983.

Ruff, L., and H. Kanamori, The rupture process and asperity distribution of three great earthquakes from long-period diffracted $P$ waves, Phys. Earth Planet. Inter.,31, 202-230, 1983.

Ruff, L.J., Tomographic imaging of seismic sources, in Seismic Tomography, edited by G. Nolet, pp. 339-366, D. Reidel, Dordrecht, Holland, 1987.

Schwartz, S.Y. and L.J. Ruff, The 1968 Tokachi-Oki and the 1969 Kurile islands earthquakes: variability in the rupture process, J. Geophys. Res., 90, 8613-8626, 1985.

Sibson, R.H., Roughness at the base of the seismogenic zone: contributing factors, J. Geophys. Res., 89, 5791-5799, 1984.

Seno, T., Intraplate seismicity in Tohoku and Hokkaido, and large interplate earthquakes: a possibility of a large interplate earthquake off the southern Sanriku coast, northern Japan, J. Phys. Earth, 27, 21-51, 1979.

Seno, T., K. Shimazaki, P. Sommerville, K. Sudo, and T. Eguchi, Rupture process of the Miyagi-Oki, Japan, earthquake of June 12, 1978, Phys. Earth Planet. Inter., $23,39-61,1980$.

Tajima , F. and H. Kanamori, Global survey of aftershock area expansion patterns, Phys. Earth Planet. Inter., 40 , 77-134, 1985.

Utsu, T., Spatial and temporal distribution of low-frequency earthquakes in Japan, J. Phys. Earth, 28, 361-384, 1980.

Yoshii, T., Crust and upper-mantle structure beneath northeastern Japan, Kagaku, 47, 170-176, 1977.

Yoshii, T., A detailed cross-section of the deep seismic zone beneath northeastern Honshu, Japan, Tectonophysics, 55, $349-360,1979$.

Larry J. Ruff and Bart W. Tichelaar, Department of Geological Sctences, The University of Michigan Ann Arbor, Michigan 48109.

(Received April 21, 1988; revised August 4, 1988; accepted August 4, 1988.) 